\title{
Influence of prolonged endurance cycling and recovery diet on intramuscular triglyceride content in trained males
}

Citation for published version (APA):

van Loon, L. J. C., Schrauwen-Hinderling, V. B., Koopman, R., Wagenmakers, A. J. M., Hesselink, M. K. C., Schaart, G., Kooi, M. E., \& Saris, W. H. M. (2003). Influence of prolonged endurance cycling and recovery diet on intramuscular triglyceride content in trained males. American Journal of Physiology : Endocrinology and Metabolism, 285(4), E804-E811. https://doi.org/10.1152/ajpendo.00112.2003

Document status and date:

Published: 01/01/2003

DOI:

10.1152/ajpendo.00112.2003

Document Version:

Publisher's PDF, also known as Version of record

\section{Please check the document version of this publication:}

- A submitted manuscript is the version of the article upon submission and before peer-review. There can be important differences between the submitted version and the official published version of record.

People interested in the research are advised to contact the author for the final version of the publication, or visit the DOI to the publisher's website.

- The final author version and the galley proof are versions of the publication after peer review.

- The final published version features the final layout of the paper including the volume, issue and page numbers.

Link to publication

\footnotetext{
General rights rights.

- You may freely distribute the URL identifying the publication in the public portal. please follow below link for the End User Agreement:

www.umlib.nl/taverne-license

Take down policy

If you believe that this document breaches copyright please contact us at:

repository@maastrichtuniversity.nl

providing details and we will investigate your claim.
}

Copyright and moral rights for the publications made accessible in the public portal are retained by the authors and/or other copyright owners and it is a condition of accessing publications that users recognise and abide by the legal requirements associated with these

- Users may download and print one copy of any publication from the public portal for the purpose of private study or research.

- You may not further distribute the material or use it for any profit-making activity or commercial gain

If the publication is distributed under the terms of Article $25 \mathrm{fa}$ of the Dutch Copyright Act, indicated by the "Taverne" license above, 


\title{
Influence of prolonged endurance cycling and recovery diet on intramuscular triglyceride content in trained males
}

\author{
Luc J. C. van Loon, Vera B. Schrauwen-Hinderling, René Koopman, Anton J. M. \\ Wagenmakers, Matthijs K. C. Hesselink, Gert Schaart, M. Eline Kooi and Wim H. \\ M. Saris \\ AJP - Endo 285:804-811, 2003. First published Jun 3, 2003; doi:10.1152/ajpendo.00112.2003
}

You might find this additional information useful...

This article cites 56 articles, 33 of which you can access free at: http://ajpendo.physiology.org/cgi/content/full/285/4/E804\#BIBL

This article has been cited by 3 other HighWire hosted articles:

Use of intramuscular triacylglycerol as a substrate source during exercise in humans L. J. C. van Loon J Appl Physiol, October 1, 2004; 97 (4): 1170-1187.

[Abstract] [Full Text] [PDF]

Intramyocellular lipid content in type 2 diabetes patients compared with overweight sedentary men and highly trained endurance athletes

L. J. C. van Loon, R. Koopman, R. Manders, W. van der Weegen, G. P. van Kranenburg and H.

A. Keizer

Am J Physiol Endocrinol Metab, September 1, 2004; 287 (3): E558-E565.

[Abstract] [Full Text] [PDF]

Intramyocellular lipids form an important substrate source during moderate intensity exercise in endurance-trained males in a fasted state

L. J. C. van Loon, R. Koopman, J. H. C. H. Stegen, A. J. M. Wagenmakers, H. A. Keizer and W.

H. M. Saris

J. Physiol., December 1, 2003; 553 (2): 611-625.

[Abstract] [Full Text] [PDF]

Updated information and services including high-resolution figures, can be found at: http://ajpendo.physiology.org/cgi/content/full/285/4/E804

Additional material and information about AJP - Endocrinology and Metabolism can be found at: http://www.the-aps.org/publications/ajpendo

This information is current as of February 23, 2005.

AJP - Endocrinology and Metabolism publishes results of original studies about endocrine and metabolic systems on any level of organization. It is published 12 times a year (monthly) by the American Physiological Society, 9650 Rockville Pike, Bethesda MD 20814-3991. Copyright @ 2005 by the American Physiological Society. ISSN: 0193-1849, ESSN: 1522-1555. Visit our website at http://www.the-aps.org/. 


\title{
Influence of prolonged endurance cycling and recovery diet on intramuscular triglyceride content in trained males
}

\author{
Luc J. C. van Loon, ${ }^{1}$ Vera B. Schrauwen-Hinderling, ${ }^{1,2}$ René Koopman, ${ }^{1}$ \\ Anton J. M. Wagenmakers, ${ }^{1}$ Matthijs K. C. Hesselink, ${ }^{3}$ \\ Gert Schaart, ${ }^{3}$ M. Eline Kooi, ${ }^{2}$ and Wim H. M. Saris ${ }^{1}$ \\ Departments of ${ }^{1}$ Human Biology and ${ }^{3}$ Movement Sciences, Nutrition Research Institute Maastricht, \\ Maastricht University, 6200 MD Maastricht, The Netherlands; and ${ }^{2}$ Department of \\ Radiology, University Hospital Maastricht, 6202 AZ Maastricht, The Netherlands
}

Submitted 18 March 2003; accepted in final form 28 May 2003

Van Loon, Luc J. C., Vera B. Schrauwen-Hinderling, René Koopman, Anton J. M. Wagenmakers, Matthijs K. C. Hesselink, Gert Schaart, M. Eline Kooi, and Wim H. M. Saris. Influence of prolonged endurance cycling and recovery diet on intramuscular triglyceride content in trained males. Am J Physiol Endocrinol Metab 285: E804-E811, 2003. First published June 3, 2003; 10.1152/ ajpendo.00112.2003.-Intramuscular triglycerides (IMTG) are assumed to form an important substrate source during prolonged endurance exercise in trained males. This study investigated the effects of endurance exercise and recovery diet on IMTG content in vastus lateralis muscle. Nine male cyclists were provided with a standardized diet for 3 days, after which they performed a 3 -h exercise trial at a $55 \%$ maximum workload. Before and immediately after exercise and after 24 and $48 \mathrm{~h}$ of recovery, magnetic resonance spectroscopy (MRS) was performed to quantitate IMTG content. Muscle biopsies were taken after $48 \mathrm{~h}$ of recovery to determine IMTG content by using quantitative fluorescence microscopy. The entire procedure was performed two times; in one trial, a normal diet containing 39\% energy (En\%) as fat was provided (NF) and in the other a typical carbohydraterich athlete's diet (LF: 24 En\% fat) was provided. During exercise, IMTG content decreased by $21.4 \pm 3.1 \%$. During recovery, IMTG content increased significantly in the NF trial only, reaching preexercise levels within $48 \mathrm{~h}$. In accord with MRS, fluorescence microscopy showed significantly higher IMTG content in the NF compared with the LF trial, with differences restricted to the type I muscle fibers $(2.1 \pm 0.2$ vs. $1.4 \pm 0.2 \%$ area lipid staining, respectively). In conclusion, IMTG content in the vastus lateralis muscle declines significantly during prolonged endurance exercise in male cyclists. When a normal diet is used, IMTG contents are subsequently repleted within $48 \mathrm{~h}$ of postexercise recovery. In contrast, IMTG repletion is impaired substantially when a typical, carbohydrate-rich athlete's diet is used. Data obtained by quantitative fluorescence microscopy correspond well with MRS results, implying that both are valid methods to quantify IMTG content.

muscle; nuclear magnetic resonance; ${ }^{1} \mathrm{H}$ magnetic resonance spectroscopy; oil red $\mathrm{O}$; exercise; intramyocellular lipid; diet

FAT AND CARBOHYDRATE are the principal substrates that fuel aerobic ATP synthesis in skeletal muscle. During

Address for reprint requests and other correspondence: L. J. C. van Loon, Dept. of Human Biology, Maastricht Univ., P.O. Box 616, 6200 MD Maastricht, The Netherlands (E-mail: L.vanLoon@ HB.unimaas.nl). moderate-intensity exercise, fat oxidation contributes about one-half of total energy expenditure, with plasma free fatty acids (FFA) as the main fat source (38, 45, 55). Recently, we quantitated FFA oxidation rates in trained male cyclists during moderate-intensity exercise, which represented $\sim 50 \%$ of total fat oxidation (55). Other fat sources contributing to total fat oxidation include plasma lipoprotein-derived triglycerides and intramuscular triglyceride (IMTG) stores. With the contribution of lipoprotein-derived triglyceride oxidation generally assumed to be of little quantitative importance $(22,39)$, IMTG stores are likely to form a major substrate source during exercise. However, the latter assumption has been disputed, as studies applying direct triglyceride measurements from muscle biopsies collected before and after exercise have reported contradicting results (57). This apparent controversy likely results from the marked between-biopsy variability in IMTG content when this extraction method is used (57).

With the introduction of magnetic resonance spectroscopy (MRS), a noninvasive means to quantitate muscle lipid content has become available (8). Several groups have applied MRS to quantitate IMTG content in various populations, which has led to the proposed relationship among increased IMTG content, obesity, and decreased insulin sensitivity $(19,28,33,41)$. The latter has strongly renewed interest in the role of exercise and diet in the regulation of IMTG storage and utilization. So far, several studies have used MRS to assess IMTG content before and after prolonged endurance exercise $(5,9,10,15,34,36,43,48)$. All of them have reported substantial $(\sim 20-40 \%)$ decreases in IMTG content after prolonged exercise. In most of these studies, IMTG content was determined by performing MRS on lower leg muscle (tibialis anterior and posterior and/or soleus muscle). The latter is in clear contrast to the vast majority of IMTG utilization studies that applied the triglyceride extraction method on muscle biopsies taken from the vastus lateralis. Clearly, MRS studies assessing IMTG content in the

The costs of publication of this article were defrayed in part by the payment of page charges. The article must therefore be hereby marked "advertisement" in accordance with 18 U.S.C. Section 1734 solely to indicate this fact. 
Table 1. Subject characteristics

\begin{tabular}{lc}
\hline \hline Age, yr & \\
Body weight, $\mathrm{kg}$ & $23.9 \pm 0.8$ \\
Height, m & $72.7 \pm 1.3$ \\
$\mathrm{BMI}, \mathrm{kg} / \mathrm{m}^{2}$ & $1.82 \pm 0.02$ \\
$\mathrm{~W}_{\max }, \mathrm{W}$ & $21.9 \pm 0.6$ \\
$\mathrm{~W}_{\max }, \mathrm{W} / \mathrm{kg}$ & $421 \pm 11$ \\
$\dot{\mathrm{V}}_{2 \max }, \mathrm{l} / \mathrm{min}$ & $5.8 \pm 0.1$ \\
$\dot{\mathrm{V}}_{2 \max }, \mathrm{ml} \cdot \mathrm{min}^{-1} \cdot \mathrm{kg}^{-1}$ & $5.0 \pm 0.2$ \\
Maximal heart rate, beats $/ \mathrm{min}$ & $68.1 \pm 1.9$ \\
\hline
\end{tabular}

Data are means $\pm \mathrm{SE} ; n=9$ subjects. BMI, body mass index; $\mathrm{W}_{\max }$, maximal workload; $\dot{\mathrm{V}}_{2 \max }$, maximal oxygen uptake.

vastus lateralis after various exercise and/or dietary interventions are warranted.

Because most exercise studies have focused on IMTG depletion, far fewer data are available on postexercise IMTG repletion $(14,15,36)$. The latter is in contrast to the numerous studies on muscle glycogen use and the efficacy of dietary interventions to accelerate muscle glycogen synthesis (27), which have led to the recommendation for endurance athletes to use high-carbohydrate, low-fat diets (42a). Interestingly, recent MRS data have shown that the use of (extremely) low-fat diets can substantially impair postexercise IMTG repletion $(14,15,36)$. In those studies, fat intake was set as low as $10-15 \%$ of total energy intake $(\mathrm{En} \%)$ in the low-fat trials, which is considerably less than the reported fat intake in elite endurance athletes $(23 \mathrm{En} \%$; see Ref. 46). The latter, of course, is still well below fat intake in a normal Western diet ( $235-40$ En\%; see Ref. 16). We questioned whether a common carbohydraterich athlete's diet limits postexercise IMTG repletion when compared with a normal diet.

MRS provides information on mixed-muscle IMTG content but does not discriminate between muscle fiber type-specific IMTG. In endurance-type exercise activities, muscle fiber recruitment mainly involves the use of type I muscle fibers (24). We recently optimized the use of fluorescence microscopy to quantify IMTG content at the muscle fiber level (32) and observed a substantial decrease in IMTG content after $2 \mathrm{~h}$ of endurance exercise in trained male athletes, which was shown to be restricted to the type I muscle fibers (54). Therefore, it would be important to determine whether differences in IMTG content after postexercise recovery on a normal or carbohydrate-rich athlete's diet are specific for muscle fiber type. In this study, we aimed to determine IMTG content in the vastus lateralis of male cyclists before and after prolonged endurance cycling. In addition, we investigated the time course of subsequent IMTG repletion after 2 days of postexercise recovery while a normal diet or a typical carbohydrate-rich athlete's diet was used. In addition to these repeated MRS measurements, muscle biopsies from the vastus lateralis were collected after 2 days of recovery to assess muscle fiber type-specific IMTG content by applying quantitative fluorescence microscopy on oil red O-stained muscle cross sections.

\section{METHODS}

Subjects. Nine male endurance-trained cyclists participated in this study. Subject characteristics are shown in Table 1. All subjects were informed about the nature and putative risks of the experimental procedures before their informed consent was obtained. This study was approved by the local Medical Ethics Committee.

Pretesting. Maximum oxygen uptake $\left(\dot{\mathrm{V}}_{2}\right.$ max $)$ and maximum workload $\left(\mathrm{W}_{\max }\right)$ were measured on an electronically braked cycle ergometer (Lode, Groningen, the Netherlands) during an incremental exhaustive exercise test $2 \mathrm{wk}$ before the first experimental trial (35). Findings were used to determine the $55 \% \mathrm{~W}_{\max }$, incorporated in the exercise trials. The $55 \% \mathrm{~W}_{\max }$ has been observed earlier to result in maximal absolute fat oxidation rates in trained male cyclists (55).

Standardization diet. All subjects received a standardization diet (30 En\% fat) during the 3 days preceding both exercise trials, which were performed in the afternoon of the 3rd day. Subjects were provided with a standard package of food products, beverages, and instant meals and were allowed to use these ad libitum. All main meals (breakfast, lunch, and dinner) and between-meal snacks were instructed to be taken at predetermined time intervals during each day. Total energy intake and macronutrient composition of actual dietary intake were calculated from the provided package minus the amount of food that was left from each package (Table 2). Subjects were instructed to refrain from heavy physical labor and/or exercise during both standardization periods.

Protocol. On the 3rd day of both standardization diets, subjects came to the laboratory at 2:00 PM. First, an MRS scan was performed to determine preexercise IMTG content. Thereafter, a blood sample was obtained from an antecubital vein. After 5 min of warming up at $100 \mathrm{~W}$, subjects started cycling at a $55 \% \mathrm{~W}_{\max }$ for a 3 -h period. Gas exchange measurements were performed each half-hour over 10-min periods (Oxycon $\beta$; Mijnhardt, Mannheim, Germany) to determine total fat and carbohydrate oxidation rates $(40,55)$. Subjects were allowed to drink water ad libitum during their first exercise trial, and the same amount of water was provided during their second trial. In case of the inability to maintain the $55 \% \mathrm{~W}_{\max }$ during the latter stages of the exercise trials, workload was decreased to $45 \% \mathrm{~W}_{\max }$. After cessation of exercise, subjects were allowed a quick shower (maximum $5 \mathrm{~min}$ ), after which a blood sample was collected and a second MRS scan was performed. Subsequently, the athletes were subjected to 2 days of either a carbohydraterich, low-fat diet (LF) or a normal-fat-containing diet (NF). Similar to the standardization diets, subjects were provided with (LF or NF) packages of food products, beverages, and instant meals and allowed to use these ad libitum. Dinners (evening meals) were all eaten under supervision at the

Table 2. Dietary intake before exercise and during recovery

\begin{tabular}{lccc}
\hline \multicolumn{1}{c}{ Dietary Intake } & $\begin{array}{c}\text { Standardization } \\
\text { Preexercise }\end{array}$ & $\begin{array}{c}\text { Low-Fat } \\
\text { Recovery }\end{array}$ & $\begin{array}{c}\text { Normal-Fat } \\
\text { Recovery }\end{array}$ \\
\hline Energy intake, MJ/day & $14 \pm 0.2$ & $14 \pm 0.5$ & $15 \pm 0.4$ \\
Fat intake, En\% & $30 \pm 0.3$ & $24 \pm 1.7$ & $39 \pm 0.3^{*}$ \\
Carbohydrate intake, En\% & $56 \pm 0.8$ & $62 \pm 2.5$ & $49 \pm 0.3^{*}$ \\
Protein intake, En\% & $13 \pm 0.2$ & $14 \pm 0.3$ & $14 \pm 0.1$ \\
\hline
\end{tabular}

Data are means \pm SE. En\%, total energy intake. * Significant difference in the contribution of fat and carbohydrate to total energy intake between the low-fat and normal-fat diets. 
laboratory after the second and third MRS scan. After finishing their LF or NF meal, subjects left the laboratory to return after 24 and $48 \mathrm{~h}$ for another MRS scan, blood sample, and subsequent dinner. In addition, after the fourth MRS scan ( $48 \mathrm{~h}$ postexercise), a muscle biopsy was collected from the vastus lateralis of the same leg that was measured in the multiple MRS scans.

Intervention diets. Subject performed two exercise trials, after which different recovery diets were provided (the LF and NF diets). Food packages and evening dinners in both diets were designed to result in an estimated fat content between 20 and 25 and 35 and $40 \mathrm{En} \%$, respectively. The LF and NF dietary intervention protocols were performed in a randomized order and were separated by a period of at least 3 wk.

MRS. Image-guided, localized, single-voxel ${ }^{1} \mathrm{H}-\mathrm{MRS}$ was performed in the vastus lateralis. All measurements were performed on a 1.5-T whole body scanner (Intera; Philips Medical Systems, Best, the Netherlands) with a flexible surface coil wrapped around the upper leg with the leg placed in the parallel position. In every subject, voxels were carefully placed at the same position for all eight measurements. Care was taken to avoid vascular structures and/or adipose tissue within the voxel. To reproduce the same voxel position, longitudinal distance from the voxel to the intercondylar eminence of the knee joint was determined in a coronal image of the upper leg. The second relaxation time $\left(T_{2}\right)$-weighted turbo spin-echo MR images, consisting of five transversal slices, were acquired at this position [repetition time/echo time (TR/TE), slice thickness $5 \mathrm{~mm}, 2,000 / 85 \mathrm{~ms}$, echo train length 12 , field of view $210 \mathrm{~mm}$, and matrix size $256 \times 256$ ] The patterns of fat distribution were used to verify the longitudinal position and as landmarks to reproduce the voxel position in the transversal plane.

${ }^{1} \mathrm{H}-\mathrm{MRS}$ spectra from the regions of interest were acquired using a point-resolved spectroscopy sequence with the following acquisition parameters: TR/TE 3,000/25 ms, 16 phase cycles, 128 averages, and 1,024 data points over $1,000 \mathrm{~Hz}$ spectral width. The voxel volume was $12 \times 11 \times 18 \mathrm{~mm}^{3}$. The water signal was suppressed using Chemically Selective Saturation. The unsuppressed water signal was measured subsequently in the same voxel under the same shimming conditions and used as a reference. For postprocessing, the spectra were fitted in the time domain using a nonlinear least squares algorithm (52) in the jmrui software package. Three peaks were fitted for intramyocellular (IMCL) and three peaks for extramyocellular (EMCL) lipids. Prior knowledge $(9,53)$ of the relative peak positions $(9,53)$ and area ratios as determined by Boesch $\mathrm{C}$ and Kooi ME (personal communications) were used as a constraint. To increase accuracy and reliability of the fitting procedure, the line width of the $\mathrm{CH}_{2}$ peak of IMCL lipids was fixed relative to the line width of the unsuppressed water peak (in the same voxel), and soft constraints were used to limit the line width and position of the $\mathrm{CH}_{2}$ peak of EMCL relative to that of the IMCL. IMCL and EMCL peaks were fitted with a Gaussian curve, while water peaks were fitted with a Lorenztian curve. The signals were corrected for $T_{1}$ and $T_{2}$ relaxation using the $T_{1}$ and $T_{2}$ relaxation times as determined by Schick and colleagues (5, $9,47,51)$. The corrected area of the $\mathrm{CH}_{2}$ peak of IMCL was expressed relative to the area of the water peak. Similar findings, with a greater coefficient of variance, were obtained when expressed relative to the creatine peak. Figure 1 shows a typical MRS acquired in the present study, showing EMCL signals to be relatively small in the vastus lateralis of these trained cyclists. The reproducibility of the IMCL quantification in the vastus lateralis was determined by measuring one

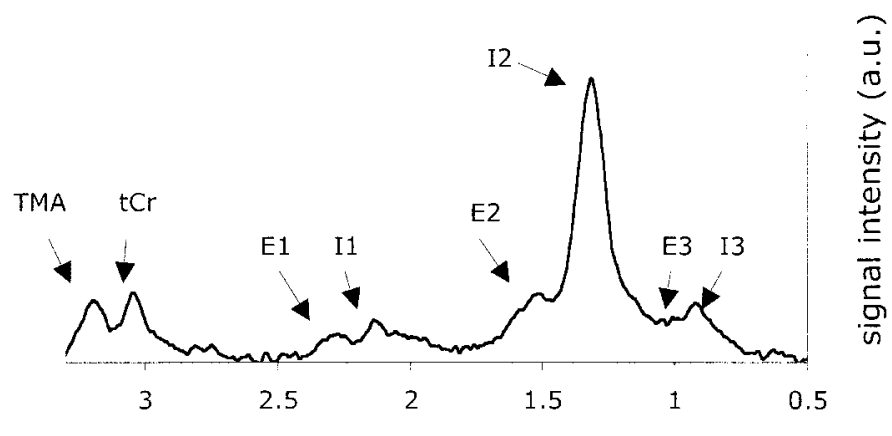

relative resonance frequency ( $\mathrm{ppm}$ )

Fig. 1. Typical spectrum acquired using image-guided, localized single-voxel ${ }^{1} \mathrm{H}$ magnetic resonance spectroscopy (MRS) in the vastus lateralis. TMA, trimethyl ammonium compounds; tCr, total creatine; $\mathrm{E} 1$, broad peak of various chemically different methylene protons of extramyocellular (EMCL; see Ref. 7) lipids; E2, methylene protons of EMCL; E3, methyl protons of EMCL; I1, broad peak of various chemically different methylene protons of intramyocellular (IMCL; see Ref. 7) lipids; I2, methylene protons of IMCL; I3, methyl protons of IMCL; AU, arbitrary units.

subject two times on several occasions. The subject left the scanning table between measurements, after which the coil was repositioned. The comparison of the IMCL quantification in corresponding voxels $(n=5)$ resulted in a coefficient of variation of $5.0 \pm 3.3 \%$, which is in accord with earlier reports on the obtained variation when measuring IMTG content by using MRS (5, 9, 47, 51).

Blood and muscle tissue analysis. Blood was collected in EDTA-containing tubes and centrifuged at $1,000 \mathrm{~g}$ and $4^{\circ} \mathrm{C}$ for $5 \mathrm{~min}$. Aliquots of plasma were frozen immediately in liquid nitrogen and stored at $-80^{\circ} \mathrm{C}$. Plasma FFA (Wako NEFA-C kit; Wako Chemicals, Neuss, Germany), free glycerol (148270; Roche Diagnostics, Indianapolis, IN), and triglyceride (GPO-trinder 337B; Sigma Diagnostics, St. Louis, MO) concentrations were analyzed using the COBAS FARA semiautomatic analyzer (Roche, Basel, Switzerland).

Muscle samples were dissected carefully, freed from any visible nonmuscle material, rapidly frozen in liquid nitrogencooled isopentane, and embedded in Tissue-Tek (Sakura Finetek, Zoeterwoude, The Netherlands). Multiple serial sections $(5 \mu \mathrm{m})$ from biopsies collected in both trials were thaw mounted together on uncoated, precleaned glass slides. To permit quantification of IMCL stained by oil red O together with immunolabeled cellular constituents, we used the protocol described by Koopman et al. (32). Briefly, cryosections were fixed in $3.7 \%$ formaldehyde for $1 \mathrm{~h}$. Slides were rinsed with deionized water, treated with $0.5 \%$ Triton X-100 in PBS, and washed with PBS. Thereafter, sections were incubated with antibodies against human laminin (polyclonal rabbit antibody; Sigma Diagnostics, Steinheim, Germany) and human myosin heavy chain (A4.840), developed by Dr. H. M. Blau (12), enabling us to visualize individual cell membranes and to determine muscle fiber type (I or II), respectively. Incubation was followed by washes in PBS, after which the appropriate conjugated antibodies GARIgG, Alexa350, and GAMIgM Alexa488 (Molecular Probes, Leiden, The Netherlands) were applied. After several washes with PBS, glass slides were immersed in the oil red $\mathrm{O}$ working solution. Oil red $\mathrm{O}$ stock solution was prepared by adding $500 \mathrm{mg}$ of oil red O (Fluka Chemie, Buchs, Switzerland) to $100 \mathrm{ml} 60 \%$ triethyl phosphate. Before staining, a 36\% triethyl phosphate working solution, containing $12 \mathrm{ml}$ of oil red $\mathrm{O}$ stock solution and $8 \mathrm{ml}$ of deionized water, was prepared and filtered to remove 
crystallized oil red $\mathrm{O}$. After $30 \mathrm{~min}$ of oil red $\mathrm{O}$ immersion, slides were rinsed with deionized water followed by a 10-min wash with tap water. Stained sections were embedded in Mowiol and covered with a coverslip. After $24 \mathrm{~h}$, slides were examined using a Nikon E800 fluorescence microscope (Uvikon; Bunnik, The Netherlands) coupled to a Basler A113 C progressive scan color CCD camera, with a Bayer color filter. Epifluorescence signal was recorded using a Texas red excitation filter $(540-580 \mathrm{~nm})$ for oil red O, a DAPI UV excitation filter $(340-380 \mathrm{~nm})$ for laminin, and an FITC excitation filter (465-495 nm) for muscle fiber type. Multiple digitally captured images ( $\times 40$ objective), at least five fields of view per muscle cross section, were processed and analyzed using Lucia 6.01 software (Nikon, Düsseldorf, Germany). The oil red $\mathrm{O}$ epifluorescence signal was quantified for each cell, within five fields of view for each muscle section. An intensity threshold representing minimal absorbance values corresponding to lipid droplets was set manually and used for all images. Total area measured and the area and number of objects emitting oil red $\mathrm{O}$ epifluorescence signal were recorded. Fiber type-specific IMTG content was expressed as the percentage of the measured area that was stained with oil red $\mathrm{O}$ in each muscle cell. Average lipid droplet size was calculated by dividing the total area of lipid stained by the total number of droplets. Lipid droplet density was calculated by dividing the total number of droplets by the total (IMCL) area measured.

Statistics. All results are expressed as means \pm SE. Statistical significance of differences between trials was assessed by paired $t$-tests. A repeated-measures ANOVA was applied to assess statistical differences over time within trials. A Sheffé post hoc test was applied to locate any differences over time. Simple regression analysis was performed on mixed-muscle IMTG content, as determined by MRS, and average muscle fiber IMTG content, as determined by quantitative fluorescence microscopy (corrected for muscle fiber type composition). Statistical significance was set at $P<$ 0.05 .

\section{RESULTS}

Exercise trials. In the exercise trials, subjects cycled for $3 \mathrm{~h}$ at an average workload of $232 \pm 6 \mathrm{~W}(55 \%$ $\left.\mathrm{W}_{\max }\right)$. Because of fatigue, power output was decreased to $45 \% \mathrm{~W}_{\max }$ in two subjects during the last $30 \mathrm{~min}$ of the 3 -h exercise period. The same procedure was repeated in the second trial. The $55 \% \mathrm{~W}_{\max }$ corresponded to $62 \pm 1 \% \dot{\mathrm{V}}_{2}$ max. Substrate use and total energy expenditure were similar in both exercise trials and are reported in Table 3. MRS quantification of IMTG content before and after the exercise trials is shown in Fig. 2. IMTG content was decreased significantly by

Table 3. Substrate use during the exercise trials before dietary intervention

\begin{tabular}{lcc}
\hline \hline & $\begin{array}{c}\text { Low-Fat Diet } \\
(n=9)\end{array}$ & $\begin{array}{c}\text { Normal-Fat Diet } \\
(n=9)\end{array}$ \\
\hline Energy expenditure, MJ & $11.7 \pm 0.21$ & $11.7 \pm 0.28$ \\
Fat oxidation, g & $100 \pm 7$ & $88 \pm 3$ \\
Carbohydrate oxidation, g & $469 \pm 20$ & $502 \pm 20$ \\
Fat oxidation, En\% & $35 \pm 2$ & $31 \pm 1$ \\
Carbohydrate oxidation, En\% & $65 \pm 2$ & $69 \pm 1$ \\
\hline
\end{tabular}

Data are means $\pm \mathrm{SE} ; n$, no. of subjects. There were no significant differences between trials.

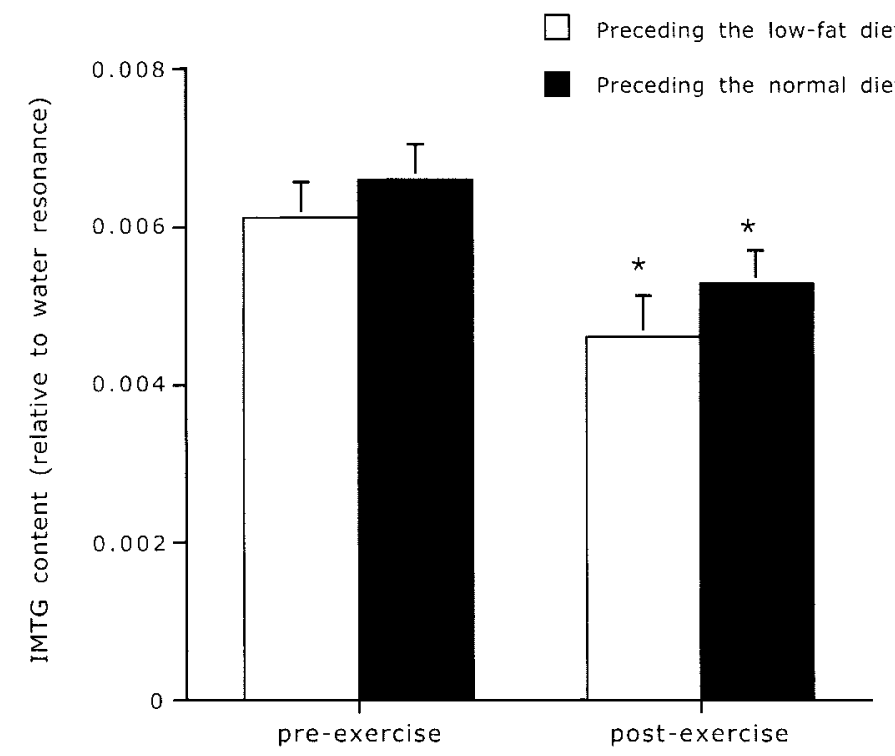

Fig. 2. Intramuscular triglyceride (IMTG) content (relative to water resonance) before and after exercise as quantitated by MRS. Data are expressed as means \pm SE. * Significantly decreased compared with preexercise values $(P<0.05)$.

$22.6 \pm 5.3$ and $20.4 \pm 3.7 \%$ in both exercise trials preliminary to the LF and NF trials, respectively $(P<$ $0.05)$. No differences were observed between trials.

Diet composition. Dietary intake during the 3-day standardization period (before the exercise trials) and subsequent dietary intake in the 2-day LF and $\mathrm{NF}$ diets are reported in Table 2. Dietary intake during both standardization periods was similar. In the recovery period, total energy and protein intake were not different between trials. However, fat and carbohydrate intake differed significantly; 24 vs. $39 \mathrm{En} \%$ fat and 62 vs. $49 \mathrm{En} \%$ carbohydrate in the LF and NF trials, respectively $(P<0.05)$.

Plasma analysis. Plasma FFA, free glycerol, and triglyceride concentrations are provided in Table 4. Plasma FFA and glycerol concentrations were increased significantly after exercise. After 24 and $48 \mathrm{~h}$ of recovery, concentrations were similar to preexercise values. Plasma triglyceride concentrations were reduced substantially after exercise and remained below baseline levels after $24 \mathrm{~h}$ of postexercise recovery. At $48 \mathrm{~h}$ postexercise, plasma triglyceride concentrations had increased significantly and were similar to preexercise levels. No significant differences were observed between trials.

IMTG repletion. In the postexercise recovery period, IMTG content was increased significantly in the NF trial only $(P<0.05)$, with post hoc analysis showing a significantly higher IMTG content after $48 \mathrm{~h}$ compared with the values reported immediately and $24 \mathrm{~h}$ after exercise. In the LF trial, no significant changes in IMTG content were observed (Fig. 3). Comparison of preexercise IMTG content with values recorded after $48 \mathrm{~h}$ of recovery showed similar content in the NF trial and a significantly lower IMTG content after $48 \mathrm{~h}$ of recovery in the LF trial. 


\begin{tabular}{|c|c|c|c|c|}
\hline & $0 \mathrm{~h}$ & $3 \mathrm{~h}$ & $24 \mathrm{~h}$ & $48 \mathrm{~h}$ \\
\hline Low-fat diet & $104 \pm 11$ & $1,425 \pm 59 *+\neq$ & $197 \pm 44$ & $177 \pm 42$ \\
\hline \multicolumn{5}{|l|}{ Free glycerol } \\
\hline Low fat diet & $58 \pm 9$ & $442 \pm 43^{*}+\ddagger$ & $67 \pm 7$ & $66 \pm 8$ \\
\hline Normal-fat diet & $45 \pm 5$ & $469 \pm 63^{* \dagger}$ & $70 \pm 6$ & $65 \pm 10$ \\
\hline \multicolumn{5}{|l|}{ Plasma triglycerides } \\
\hline
\end{tabular}

Data are means \pm SE. Plasma free fatty acid, glycerol, and triglyceride concentrations before exercise $(0 \mathrm{~h})$, within 5 min after exercise $(3$ h), and 24 and $48 \mathrm{~h}$ postexercise. Plasma free fatty acid, glycerol, and triglyceride concentrations are expressed in $\mu$ mol/l. * Significantly different from baseline value $(0)$. † Significantly different from values at $24 \mathrm{~h}$ postexercise. $†$ Significantly different from values at $48 \mathrm{~h}$ postexercise. There were no significant differences between trials.

In accord with the MRS data, muscle tissue analysis for IMTG quantification using quantitative fluorescent microscopy on oil red O-stained muscle cross sections showed significantly higher IMCL content in the type I fibers after $48 \mathrm{~h}$ of recovery in the NF compared with the LF trial (Table 5; $P<0.05$ ). The higher lipid content was accounted for by a significantly greater lipid droplet size and an increased lipid droplet density. IMCL content in the type II fibers was not different between trials. Lipid content in the type II fibers was significantly lower compared with the type I fibers. The latter was accounted for by a lower lipid droplet density $(P<0.05)$ but not lipid droplet size (not significant).

To enable a direct comparison between the data on IMTG content in mixed muscle as determined by MRS and muscle fiber type-specific IMTG content as determined by quantitative fluorescence microscopy on oil red O-stained muscle cross sections, we corrected the latter for muscle fiber type composition (Table 5). Muscle fiber type composition of the multiple muscle cross

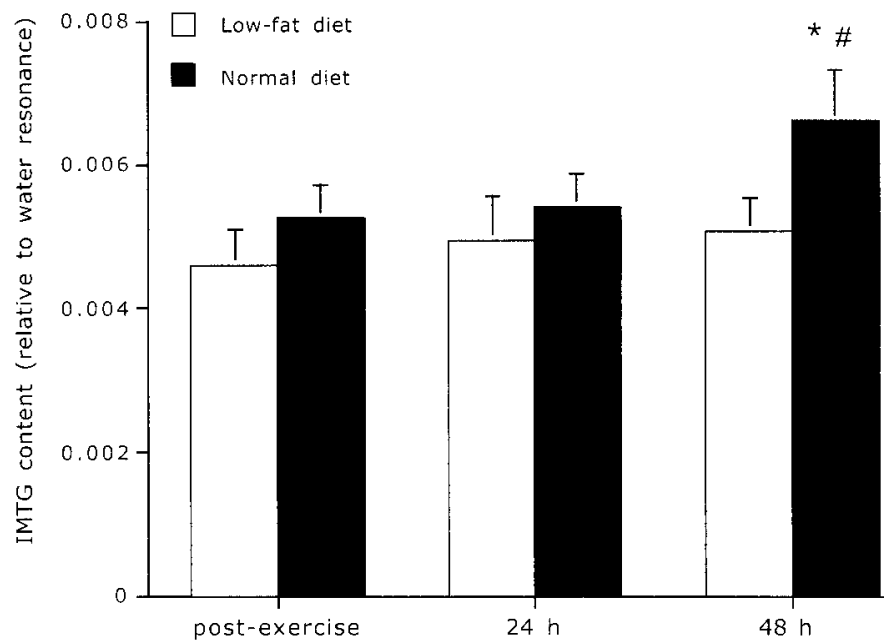

Fig. 3. IMTG (relative to water resonance) immediately after exercise and after 24 and $48 \mathrm{~h}$ of recovery on a low-fat or normalfat-containing diet, as quantitated by MRS. Data are expressed as means $\pm \mathrm{SE}$. * Significantly higher compared with baseline (postexercise) value. \#Significantly higher compared with the value observed after $24 \mathrm{~h}$ of recovery. sections showed an average $58 \pm 4 \%$ type I and $42 \pm$ $4 \%$ type II fibers. Comparison of the data on (mixedmuscle) IMTG content after $48 \mathrm{~h}$ of postexercise recovery on both the LF and NF diets using both methods revealed a strong significant correlation $(R=0.6 ; P=$ $0.01)$.

\section{DISCUSSION}

In the present study, we observed a progressive increase in whole body fat oxidation rates during exercise, resulting in an average total of $94 \pm 4 \mathrm{~g}$ of fat oxidized within the 3 -h exercise trials (Table 3). Concomitantly, IMTG content in the vastus lateralis muscle, as measured by MRS, was reduced substantially by $21 \pm 3 \%$ after exercise (Fig. 2). The observed decrease is in line with other MRS studies reporting similar $(\sim 20-40 \%)$ reductions in IMTG content in the tibialis anterior and soleus muscle before and after prolonged running or cycling exercise $(5,9,10,15,34,36,43)$. We converted the IMTG data (Fig. 2) to absolute muscle concentrations using formulas and assumptions as published by Boesch et al. (5). Subsequently, IMTG contents before and after exercise in the vastus lateralis muscle averaged $7.9 \pm 0.6$ (pre) and $5.9 \pm 0.7$ (post) and $8.5 \pm 0.6$ (pre) and $6.8 \pm 0.6$ (post) $\mathrm{mmol} / \mathrm{kg}$ wet

Table 5. Oil red $O$ staining: muscle triglyceride content $48 \mathrm{~h}$ postexercise

\begin{tabular}{lcc}
\hline \hline & $\begin{array}{c}\text { Low-Fat Diet } \\
(n=9)\end{array}$ & $\begin{array}{c}\text { Normal-Fat Diet } \\
(n=9)\end{array}$ \\
\hline & Type I fibers & \\
IMTG content, \% & $1.39 \pm 0.21$ & $2.09 \pm 0.24^{*}$ \\
Droplet size, $\mu \mathrm{m}^{2} /$ droplet & $0.87 \pm 0.06$ & $1.00 \pm 0.04^{*}$ \\
Droplet density, droplets/ $\mathrm{mm}^{2}$ & $0.016 \pm 0.002$ & $0.020 \pm 0.002^{*}$ \\
Fiber type content, \% & $55 \pm 7$ & $60 \pm 6$
\end{tabular}

IMTG content, $\%$ Type II fibers

$0.51 \pm 0.11$

Droplet density, droplets $/ \mu \mathrm{m}^{2} \quad 0.010 \pm 0.002 \dagger$ $0.66 \pm 0.12$

Fiber type content, \%

$0.94+0.07$

$0.009 \pm 0.003 \dagger$

Data are means $\pm \mathrm{SE} ; n$, no. of subjects. IMTG, intramuscular triglycerides. * Significantly higher in the normal-fat trial compared with the low-fat trial. $†$ Significantly lower compared with the type I muscle fibers. 
muscle, preceding the $\mathrm{LF}$ and NF diets, respectively. These absolute IMTG concentrations observed in the vastus lateralis are well above IMTG content reported for tibialis anterior, tibialis posterior, and/or soleus muscle $(1,2,15,26,28,29)$ and confirms that there are substantial differences in IMTG content between different muscle groups. The latter seems to be, at least partly, explained by differences in muscle fiber type composition (26).

Our data clearly show that IMTG stores in the vastus lateralis form an important substrate source during prolonged (cycling) exercise in male athletes. This confirms conclusions from stable isotope studies reporting that $\sim 50 \%$ of total fat oxidation is accounted for by plasma FFA oxidation, suggesting that other substrate sources like IMTG play a substantial role in energy provision during exercise $(22,38,45,55)$. However, as noted in the introduction, the importance of IMTG stores as a substrate source has been disputed as some $(4,11,13,17,20,25,42,56)$, but certainly not all, studies $(3,21,30,31,44,49,50,58)$ using the biochemical triglyceride extraction method on muscle samples collected before and after exercise have been able to show a significant decline in IMTG content after prolonged endurance exercise. The apparent controversy, elegantly described by Watt et al. (57), can be explained partly by the marked between-biopsy variability $(\sim 24 \%)$ that has been reported when this technique (58) is used. Whether the high variability in muscle IMTG content is the result of the contamination of the obtained muscle samples with EMCL triglycerides $(57,58)$ and/or simply because of high variability in IMTG content between various muscle sections (50) is not clear (57). In accord with the apparent problems when using the biochemical triglyceride extraction method, Howald et al. (23) reported a good correlation between IMTG content in the tibialis anterior as determined by MRS and electron microscopy (EM), but the results from the muscle triglyceride extraction method did not correlate well with the results obtained by either EM or MRS.

In the postexercise phase, we observed a significant increase in IMTG content over the 48-h recovery period only when the NF diet was used. After $24 \mathrm{~h}$ of postexercise recovery, IMTG content was still low and did not differ from IMTG contents observed immediately after cessation of exercise (Fig. 2). Similarly, plasma triglyceride concentrations remained substantially lower compared with preexercise values (Table 4 ). After $48 \mathrm{~h}$ of postexercise recovery, IMTG content and plasma triglyceride levels had increased significantly on the $\mathrm{NF}$ diet. When IMTG content after $48 \mathrm{~h}$ of recovery on the NF diet was compared with the corresponding preexercise values, no significant differences were observed. Therefore, we conclude that, with a normal diet during recovery from prolonged endurance exercise, IMTG stores in the vastus lateralis can be replenished fully within $48 \mathrm{~h}$. These findings seem to be somewhat different from those of Larson-Meyer et al. (36), who observed full restoration of the IMTG content in the soleus muscle of seven female endurance runners within $\sim 22 \mathrm{~h}$ of recovery from a 2 -h treadmill run when using a similar normal-fat-containing diet (35 En\%). The apparent discrepancy could likely be explained by a more extensive depletion of the IMTG stores in the vastus lateralis muscle after the 3 -h cycling protocol in the present study. In addition, gender differences in IMTG use and/or storage $(44,50)$ and differences in the activation pattern of the different muscle groups during running or cycling are likely to contribute to the apparent differences in the observed time course of IMTG repletion.

In line with other studies on postexercise IMTG repletion $(15,36)$, we show that IMTG repletion is impaired substantially when a low-fat diet is used. In the present study, IMTG content did not increase during $48 \mathrm{~h}$ of postexercise recovery when a typical low-fat athlete's diet (24 En\% fat) was used, with IMTG content still being significantly lower after $48 \mathrm{~h}$ of recovery compared with preexercise values $(P<0.05)$. In agreement, others have reported that ingestion of a low-fat diet does not allow IMTG content to return to preexercise levels within 30 (15), 22, and 70 (36) h of postexercise recovery. Although in those studies more extreme low-fat diets (10-15 En\% fat) were applied, the present study shows that even a commonly used carbohydrate-rich athlete's diet containing 24 En\% fat (46) is insufficient to enable a full restoration of the IMTG stores within $48 \mathrm{~h}$. As such, it could be speculated that such a dietary strategy potentially limits performance during periods of repeated bouts of prolonged endurance exercise. However, optimizing performance capacity by maximizing endogenous substrate repletion in the postexercise phase also includes the need to optimize postexercise muscle glycogen synthesis. Clearly, when fat intake is decreased to favor carbohydrate ingestion, IMTG restoration will become impaired. In reverse, when fat intake is favored to maximize IMTG repletion, muscle glycogen storage could prove to become suboptimal. Obviously, diets with an opposite fat-to-carbohydrate ratio seem to be preferred for IMTG or glycogen repletion, which makes the choice of postexercise dietary strategy controversial. As recently suggested by Décombaz et al. (15), a high-carbohydrate diet provided immediately postexercise followed by a normal- to high-fat diet could prove to optimize IMTG content without compromising muscle glycogen storage. More research is warranted to determine the best dietary strategy to optimize both IMTG and muscle glycogen storage.

The use of oil red $\mathrm{O}$ staining on muscle cross sections and subsequent quantification of the staining intensity by fluorescence microscopy have been optimized recently (32) and enable direct and fiber type-selective quantification of IMCL lipid content. Because of the invasiveness of the percutaneous muscle biopsies, muscle samples were only collected after $48 \mathrm{~h}$ of recovery in both trials. Similar to the data acquired by MRS, quantitative fluorescence microscopy showed substantially higher IMTG content after the use of the NF vs. the LF diet after $48 \mathrm{~h}$ of recovery. In agreement, a significant correlation was observed between the data 
on (mixed-muscle) IMTG content obtained by the use of both methods $(R=0.6 ; P<0.01)$. Subsequently, our data imply that both MRS and quantitative microscopy on oil red O-stained muscle cross sections represent valid methods to quantify IMTG content. With MRS being unable to provide information on fiber typespecific IMCL lipid content, we applied fluorescence microscopy to determine whether potential differences in IMTG content after the use of the NF and LF diet could be fiber type specific. Clearly, the higher mixedmuscle IMTG content after the NF vs. LF diet was explained by a significantly higher IMTG content in the type I but not the type II muscle fibers (Table 5). The latter is important, since muscle fiber type recruitment during endurance-type exercise predominantly relies on the use of type I muscle fibers (24), which have been shown to contain about three- to fourfold more lipid than type II fibers $(18,37)$. In agreement, we recently observed a substantial decrease in IMTG content, which was shown to be restricted to the type I muscle fibers, after prolonged (2-h) endurance exercise in trained male athletes (Van Loon LJC, Greenhaff PL, Constantin-Teodosiu D, Saris WHM, and Wagenmakers AJM, unpublished observations). Subsequently, the repletion of type I muscle fiber IMTG content could prove to be of great functional importance. More studies are warranted to provide detailed insight into muscle fiber type-specific IMTG utilization, the extent of IMTG depletion, and the time course of subsequent IMTG repletion during postexercise recovery.

In summary, the present study shows that IMTG content in the vastus lateralis muscle is reduced substantially after prolonged endurance cycling exercise in trained male athletes. During postexercise recovery, IMTG repletion is impaired substantially when a carbohydrate-rich athlete's diet is used, which is typically low in fat. As such, IMTG stores are not replenished within $48 \mathrm{~h}$, which is in contrast to the situation when an NF diet is used. These results imply that carbohydrate-rich diets, as generally recommended to endurance athletes, are insufficient in providing ample substrate for IMTG repletion in male athletes. The latter could prove to result in suboptimal performance capacity during periods in which prolonged endurance exercise trials are performed repeatedly. In addition, data on IMTG content as obtained by using quantitative fluorescence microscopy on oil red O-stained muscle cross sections correspond well with MRS results, implying that both are valid methods to quantify IMCL lipid content.

We gratefully acknowledge the analytic assistance of Jos Stegen and Joan Senden and the enthusiastic support of the subjects who volunteered to participate in these trials.

The monoclonal antibody A4.840 developed by Dr. H. M. Blau was obtained from the Developmental Studies Hybridoma Bank developed under the auspices of the National Institute of Child Health and Human Development and maintained by the University of Iowa, Department of Biological Science.

\section{DISCLOSURES}

L. J. C. van Loon was supported by an individual fellowship from the Netherlands Organization for Scientific Research.

\section{REFERENCES}

1. Anderwald C, Bernroider E, Krssak M, Stingl H, Brehm A, Bischof MG, Nowotny P, Roden M, and Waldhausl W. Effects of insulin treatment in type 2 diabetic patients on intracellular lipid content in liver and skeletal muscle. Diabetes 51: 3025-3032, 2002.

2. Bachmann OP, Dahl DB, Brechtel K, Machann J, Haap M, Maier T, Loviscach M, Stumvoll M, Claussen CD, Schick F, Haring HU, and Jacob S. Effects of intravenous and dietary lipid challenge on intramyocellular lipid content and the relation with insulin sensitivity in humans. Diabetes 50: 2579-2584, 2001.

3. Bergman BC, Butterfield GE, Wolfel EE, Casazza GA, Lopaschuk GD, and Brooks GA. Evaluation of exercise and training on muscle lipid metabolism. Am J Physiol Endocrinol Metab 276: E106-E117, 1999.

4. Bergstrom J, Hultman E, and Saltin B. Muscle glycogen consumption during cross-country skiing (the Vasa ski race). Int Z Angew Physiol Einschl Arbeitsphysiol 31: 71-75, 1973.

5. Boesch C, Decombaz J, Slotboom J, and Kreis R. Observation of intra-myocellular lipids by means of ${ }^{1} \mathrm{H}$ magnetic resonance spectroscopy. Proc Nutr Soc 58: 841-850, 1999.

7. Boesch C and Kreis R. MR-spectroscopy (MRS) of different nuclei applied to human muscle: additional information obtained by ${ }^{1} \mathrm{H}-\mathrm{MRS}$. Int $J$ Sports Med 18: S310-S312, 1997.

8. Boesch C and Kreis R. Observation of intramyocellular lipids by ${ }^{1} \mathrm{H}$-magnetic resonance spectroscopy. Ann NY Acad Sci 904: 25-31, 2000.

9. Boesch C, Slotboom J, Hoppeler H, and Kreis R. In vivo determination of intramyocellular lipids in human muscle by means of localized ${ }^{1} \mathrm{H}-\mathrm{MR}$-spectroscopy. Magn Reson Med 37: 484493, 1997.

10. Brechtel K, Niess AM, Machann J, Rett K, Schick F, Claussen CD, Dickhuth HH, Haering HU, and Jacob S. Utilisation of intramyocellular lipids (IMCLs) during exercise as assessed by proton magnetic resonance spectroscopy $\left({ }^{1} \mathrm{H}-\mathrm{MRS}\right)$. Horm Metab Res 33: 63-66, 2001.

11. Carlson LA, Ekelund LG, and Froberg SO. Concentration of triglycerides, phospholipids and glycogen in skeletal muscle and of free fatty acids and beta-hydroxybutyric acid in blood in man in response to exercise. Eur J Clin Invest 1: 248-254, 1971.

12. Cho M, Webster SG, and Blau HM. Evidence for myoblastextrinsic regulation of slow myosin heavy chain expression during muscle fiber formation in embry-onic development. $J$ Cell Biol 121: 795-810, 1993.

13. Cleroux J, Van Nguyen P, Taylor AW, and Leenen FH. Effects of $\beta_{1}$ vs. $\beta_{1}+\beta_{2}$-blockade on exercise endurance and muscle metabolism in humans. J Appl Physiol 66: 548-554, 1989.

14. Décombaz J, Fleith M, Hoppeler H, Kreis R, and Boesch C. Effect of diet on the replenishment of intramyocellular lipids after exercise. Eur J Nutr 39: 244-247, 2000.

15. Décombaz J, Schmitt B, Ith M, Decarli B, Diem P, Kreis R, Hoppeler H, and Boesch C. Postexercise fat intake repletes intramyocellular lipids but no faster in trained than in sedentary subjects. Am J Physiol Regul Integr Comp Physiol 281: R760R769, 2001.

16. De Castro JM. What are the major correlates of macronutrient selection in Western populations? Proc Nutr Soc 58: 755-763, 1999.

17. Essen B, Hagenfeldt L, and Kaijser L. Utilization of bloodborne and intra-muscular substrates during continuous and intermittent exercise in man. J Physiol 265: 489-506, 1977.

18. Essen B, Jansson E, Henriksson J, Taylor AW, and Saltin B. Metabolic characteristics of fibre types in human skeletal muscle. Acta Physiol Scand 95: 153-165, 1975.

19. Forouhi NG, Jenkinson G, Thomas EL, Mullick S, Mierisova S, Bhonsle U, McKeigue PM, and Bell JD. Relation of triglyceride stores in skeletal muscle cells to central obesity and insulin sensitivity in European and South Asian men. Diabetologia 42: 932-935, 1999.

20. Froberg SO and Mossfeldt F. Effect of prolonged strenuous exercise on the concentration of triglycerides, phospholipids and glycogen in muscle of man. Acta Physiol Scand 82: 167-171, 1971. 
21. Guo Z, Burguera B, and Jensen MD. Kinetics of intramuscular triglyceride fatty acids in exercising humans. $J$ Appl Physiol 89: 2057-2064, 2000.

22. Havel RJ, Pernow B, and Jones NL. Uptake and release of free fatty acids and other metabolites in the legs of exercising men. J Appl Physiol 23: 90-99, 1967.

23. Howald H, Boesch C, Kreis R, Matter S, Billeter R, EssenGustavsson B, and Hoppeler H. Content of intramyocellular lipids derived by electron microscopy, biochemical assays, and ${ }^{1} \mathrm{H}-\mathrm{MR}$ spectroscopy. J Appl Physiol 92: 2264-2272, 2002.

24. Hultman E. Fuel selection, muscle fibre. Proc Nutr Soc 54: $107-21,1995$.

25. Hurley BF, Nemeth PM, Martin WH, Hagberg JM, Dalsky GP, and Holloszy JO. Muscle triglyceride utilization during exercise: effect of training. J Appl Physiol 60: 562-567, 1986.

26. Hwang JH, Pan JW, Heydari S, Hetherington HP, and Stein DT. Regional differences in intramyocellular lipids in humans observed by in vivo ${ }^{1} \mathrm{H}-\mathrm{MR}$ spectroscopic imaging. J Appl Physiol 90: 1267-1274, 2001.

27. Ivy JL. Muscle glycogen synthesis before and after exercise. Sports Med 11: 6-19, 1991.

28. Jacob S, Machann J, Rett K, Brechtel K, Volk A, Renn W, Maerker E, Matthaei S, Schick F, Claussen CD, and Haring HU. Association of increased intra-myocellular lipid content with insulin resistance in lean nondiabetic offspring of type 2 diabetic subjects. Diabetes 48: 1113-1119, 1999.

29. Kautzky-Willer A, Krssak M, Winzer C, Pacini G, Tura A, Farhan S, Wagner O, Brabant G, Horn R, Stingl H, Schneider B, Waldhausl W, and Roden M. Increased intramyocellular lipid concentration identifies impaired glucose metabolism in women with previous gestational diabetes. Diabetes 52: 244-251, 2003.

30. Kiens B, Essen-Gustavsson B, Christensen NJ, and Saltin B. Skeletal muscle substrate utilization during submaximal exercise in man: effect of endurance training. $J$ Physiol 469: 459478,1993

31. Kiens B and Richter EA. Utilization of skeletal muscle triacylglycerol during postexercise recovery in humans. Am J Physiol Endocrinol Metab 275: E332-E337, 1998.

32. Koopman R, Schaart G, and Hesselink MK. Optimisation of oil red $\mathrm{O}$ staining permits combination with immunofluorescence and automated quantification of lipids. Histochem Cell Biol 116: 63-68, 2001.

33. Krssak M, Falk Petersen K, Dresner A, DiPietro L, Vogel SM, Rothman DL, Roden M, and Shulman GI. Intramyocellular lipid concentrations are correlated with insulin sensitivity in humans: a ${ }^{1} \mathrm{H}$ NMR spectroscopy study. Diabetologia 42 : 113-116, 1999.

34. Krssak M, Petersen KF, Bergeron R, Price T, Laurent D, Rothman DL, Roden M, and Shulman GI. Intramuscular glycogen and intramyocellular lipid utilization during prolonged exercise and recovery in man: ${ }^{13} \mathrm{C}$ and ${ }^{1} \mathrm{H}$ nuclear magnetic resonance spectroscopy study. J Clin Endocrinol Metab 85: 748-754, 2000.

35. Kuipers H, Verstappen FT, Keizer HA, Geurten P, and van Kranenburg G. Variability of aerobic performance in the laboratory and its physiologic correlates. Int J Sports Med 6: 197-201, 1985.

36. Larson-Meyer DE, Newcomer BR, and Hunter GR. Influence of endurance running and recovery diet on intramyocellular lipid content in women: a ${ }^{1} \mathrm{H}$ NMR study. Am J Physiol Endocrinol Metab 282: E95-E106, 2002.

37. Malenfant P, Joanisse DR, Theriault R, Goodpaster BH, Kelley DE, and Simoneau JA. Fat content in individual muscle fibers of lean and obese subjects. Int Obes Relat Metab Disord 25: 1316-1321, 2001

38. Martin WHD, Dalsky GP, Hurley BF, Matthews DE, Bier DM, Hagberg JM, Rogers MA, King DS, and Holloszy JO. Effect of endurance training on plasma free fatty acid turnover and oxidation during exercise. Am J Physiol Endocrinol Metab 265: E708-E714, 1993.

39. Oscai LB, Essig DA, and Palmer WK. Lipase regulation of muscle triglyceride hydrolysis. J Appl Physiol 69: 1571-1577, 1990.

40. Peronnet $\mathbf{F}$ and Massicotte $\mathbf{D}$. Table of nonprotein respiratory quotient: an update. Can J Sport Sci 16: 23-29, 1991.
41. Perseghin G, Scifo P, De Cobelli F, Pagliato E, Battezzati A, Arcelloni C, Vanzulli A, Testolin G, Pozza G, Del Maschio A, and Luzi L. Intramyocellular triglyceride content is a determinant of in vivo insulin resistance in humans: a ${ }^{1} \mathrm{H}-{ }^{13} \mathrm{C}$ nuclear magnetic resonance spectroscopy assessment in offspring of type 2 diabetic parents. Diabetes 48: 1600-1606, 1999.

42. Phillips SM, Green HJ, Tarnopolsky MA, Heigenhauser GJ, and Grant SM. Progressive effect of endurance training on metabolic adaptations in working skeletal muscle. Am J Physiol Endocrinol Metab 270: E265-E272, 1996.

42a.Position of the American Dietetic Association, Dietitians of Canada, and the American College of Sports Medicine. Nutrition and Athletic Performance. J Am Diet Assoc 100: 1543-56, 2000.

43. Rico Sanz J, Moosavi M, Thomas EL, McCarthy J, Coutts GA, Saeed N, and Bell JD. In vivo evaluation of the effects of continuous exercise on skeletal muscle triglycerides in trained humans. Lipids 35: 1313-1318, 2000.

44. Roepstorff C, Steffensen CH, Madsen M, Stallknecht B, Kanstrup IL, Richter EA, and Kiens B. Gender differences in substrate utilization during submaximal exercise in endurancetrained subjects. Am J Physiol Endocrinol Metab 282: E435E447, 2002.

45. Romijn JA, Coyle EF, Sidossis LS, Gastaldelli A, Horowitz JF, Endert E, and Wolfe RR. Regulation of endogenous fat and carbohydrate metabolism in relation to exercise intensity and duration. Am J Physiol Endocrinol Metab 265: E380-E391, 1993.

46. Saris WH, van Erp-Baart MA, Brouns F, Westerterp KR, and ten Hoor F. Study on food intake and energy expenditure during extreme sustained exercise: the Tour de France. Int J Sports Med 10, Suppl 1: May 10: S26-S31, 1989.

47. Schick F, Eismann B, Jung WI, Bongers H, Bunse M, and Lutz O. Comparison of localized proton NMR signals of skeletal muscle and fat tissue in vivo: two lipid compartments in muscle tissue. Magn Reson Med 29: 158-167, 1993.

48. Schrauwen-Hinderling VB, Schrauwen P, Hesselink MK, Van Engelshoven JM, Nicolay K, Saris WH, Kessels AG, and Kooi ME. The increase in intramyocellular lipid content is a very early response to training. J Clin Endocrinol Metab 88: 1610-1616, 2003.

49. Starling RD, Trappe TA, Parcell AC, Kerr CG, Fink WJ, and Costill DL. Effects of diet on muscle triglyceride and endurance performance. J Appl Physiol 82: 1185-1189, 1997.

50. Steffensen CH, Roepstorff $\mathbf{C}$, Madsen $M$, and Kiens $B$. Myocellular triacylglycerol breakdown in females but not in males during exercise. Am J Physiol Endocrinol Metab 282: E634-E642, 2002.

51. Szczepaniak LS, Babcock EE, Schick F, Dobbins RL, Garg A, Burns DK, McGarry JD, and Stein DT. Measurement of intracellular triglyceride stores by ${ }^{1} \mathrm{H}$ spectroscopy: validation in vivo. Am J Physiol Endocrinol Metab 276: E977-E989, 1999.

52. Van den Boogaart AH, van Huffel P, Graveron-Demilly S, Van Ormondt D, and De Beer R. MRVI; a graphical user interface for accurate routine MRS data analysis. Proc Eur Soc Magnetic Resonance Med Biol 13th Annual Meeting, 1996, p. 318.

53. Vanhamme L, Van den Boogaart A, and van Huffel P. Improved method for accurate and efficient quantification of MRS data with use of prior knowledge. J Magn Reson 129: 35-43, 1997.

55. Van Loon LJC, Greenhaff PL, Constantin-Teodosiu D, Saris WHM, and Wagenmakers AJM. The effects of increasing exercise intensity on muscle fuel utilisation in humans. J Physiol 536: 295-304, 2001.

56. Watt MJ, Heigenhauser GJ, Dyck DJ, and Spriet LL. Intramuscular triacylglycerol, glycogen and acetyl group metabolism during $4 \mathrm{~h}$ of moderate exercise in man. J Physiol 541: 969-978, 2002.

57. Watt MJ, Heigenhauser GJ, and Spriet LL. Intramuscular triacylglycerol utilization in human skeletal muscle during exercise: is there a controversy? J Appl Physiol 93: 1185-1195, 2002.

58. Wendling PS, Peters SJ, Heigenhauser GJ, and Spriet LL. Variability of triacylglycerol content in human skeletal muscle biopsy samples. J Appl Physiol 81: 1150-1155, 1996. 